\title{
Flying Wings. A New Paradigm for Civil Aviation?
}

\section{R. Martinez-Val}

Over the last 50 years, commercial aviation has been mainly based what is currently called the conventional layout, characterized by a slender fuselage mated to a high aspect ratio wing, with aft-tail planes and pod-mounted engines under the wing. However, it seems that this primary configuration is approaching an asymptote in its productivity and performance characteristics. One of the most promising configurations for the future is the flying wing in its distinct arrangements: blended-wing-body, $C$-wing, tail-less aircraft, etc. These layouts might provide significant fuel savings and, hence, a decrease in pollution. This configuration would also reduce noise in take-off and landing. All this explains the great deal of activity carried out by the aircraft industry and by numerous investigators to perform feasibility and conceptual design studies of this aircraft layout to gain better knowledge of its main characteristics: productivity, airport compatibility, passenger acceptance, internal architecture, emergency evacuation, etc. The present paper discusses the main features of flying wings, their advantages over conventional competitors, and some key operational issues, such as evacuation and vortex wake intensity.

Keywords: flying wing, blended-wing-body, conceptual design, civil aviation.

\section{Introduction}

Civil aviation has continuously been progressing since the onset of commercial flights in Florida in 1916 and the appearance of scheduled international links just after the end of the First World War [1]. To sustain and foster this progress, all branches of the aeronautical sciences and technology have also experienced a breathtaking evolution. The contributions of aerodynamics, structures, propulsion, avionics and materials have been essential [2], and have been so impacting that air travel has changed our notion of time and space, and our way of life.

Many legendary airplanes have paved the way of civil aviation. To mention but a few, let us arrange a short list: Douglas DC-3, Lockheed Super Constellation, Boeing B707, Sud Aviation Caravelle, Boeing B747, BAC-SA Concorde...

However, a certain paradox has arisen in the midst of this development: an airplane enthusiast looking at the runways from an airport spectators terrace would see the same shapes nowadays as 30 years back. The vast majority of the flying vehicles belong to the so-called conventional configuration [2].

Around 60 years ago, Boeing engineers created a new jet airplane concept characterized by a slender fuselage mated to a high aspect ratio swept wing, horizontal and vertical stabilizers attached to the rear fuselage, and pod-mounted engines under the wing. The aircraft, named B47, was a bomber, designed to fly at high subsonic speeds [3]. In subsequent years, most engineers working around the world on new airliners equipped with jet engines, to fly faster and higher, followed the same concept. A variant, with pod-mounted engines attached to the rear fuselage, soon appeared and was better suited for small and medium-size transport airplanes. Both the basic concept and the variant are still in use in current designs at the beginning of the $21^{\text {st }}$ Century (see Fig. 1). The conservatism in maintaining the configuration over decades contrasts sharply with the enormous efforts made in aerodynamics, materials, propulsion, etc [2]. The average lift over drag ratio in cruise has increased more than 30 percent since the advent of jet airliners. At the same time, new alloys and composite materials have reduced the structural weight by nearly 40 percent in the same period. The engines have halved their specific fuel consumption in the last five decades.
These improvements have resulted in an outstanding decrease in direct operating costs. Flying has become an ordinary and popular way of travel in the rich countries [4], and a similar societal transformation is occurring in the developing countries led by the continuous decrease in air fares. Consequently, the centre of gravity of civil aviation is changing [5-7]. In the recent past the USA, in first place, and Europe, in second place led the rankings. By around 2020, Europe will be number one (as depicted in Fig. 2), and some years later the Asia-Pacific Rim will overtake Europe in terms of revenue pas-

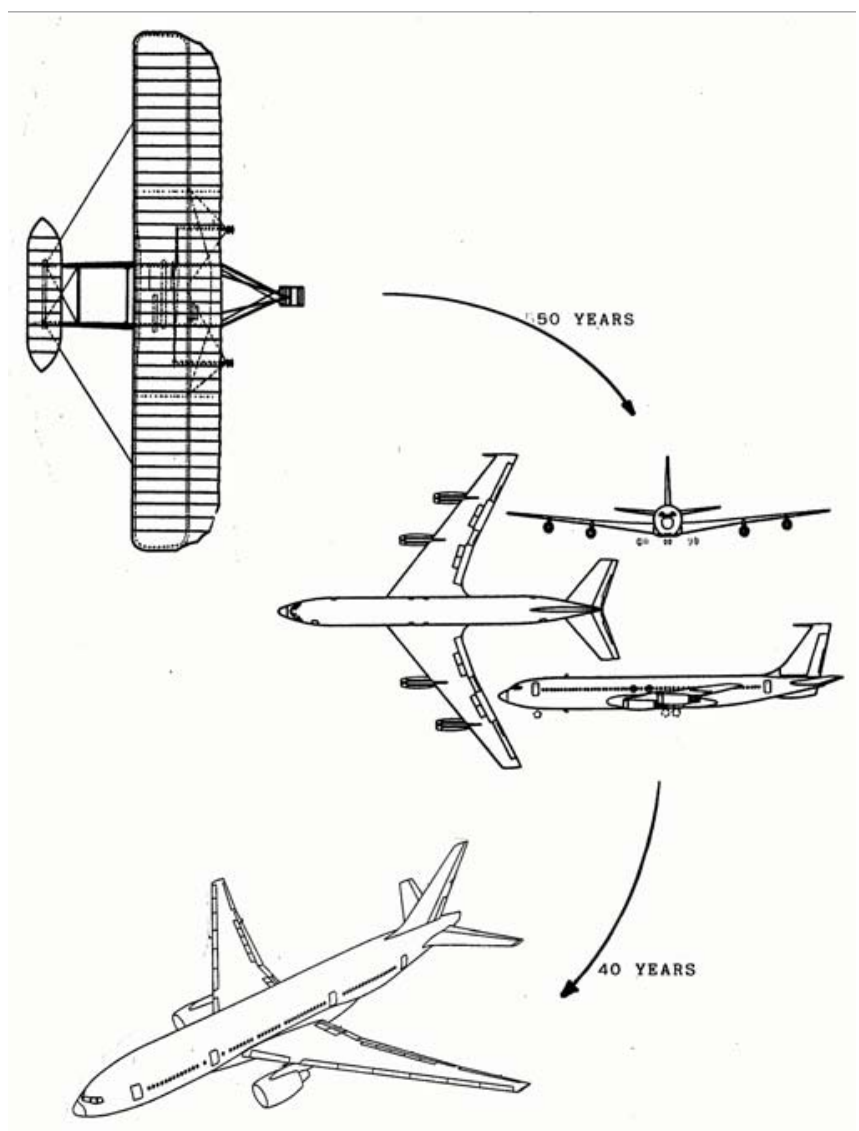

Fig. 1: Great change and steadiness evolution in 100 years of aviation 


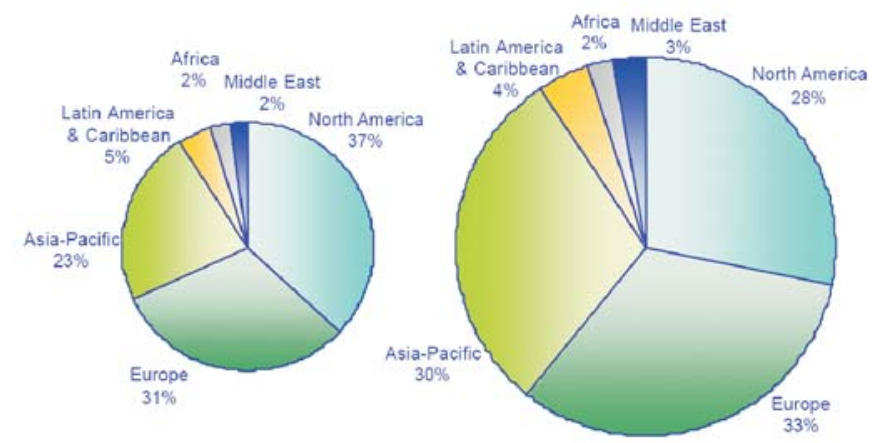

Fig. 2: Evolution and geographical distribution of world air traffic at the beginning of the $21^{\text {st }}$ Century in terms of revenue passenger kilometres (RPK). On the left, data for year 2000 (3.3 trillion RPK). On the right, year 2020 (8.3 trillion RPK)

senger-kilometres and air freight. Fig. 3 explains why: the number of air trips per capita in rich countries hardly varies with wealth; meanwhile a mild increase in per capita income in the crowded poor countries (such as China, India, etc.) translates into much higher air traffic demand.

The size of the airplanes is also entrained by this scenario. Current airliners have an average size of 180 seats. Those

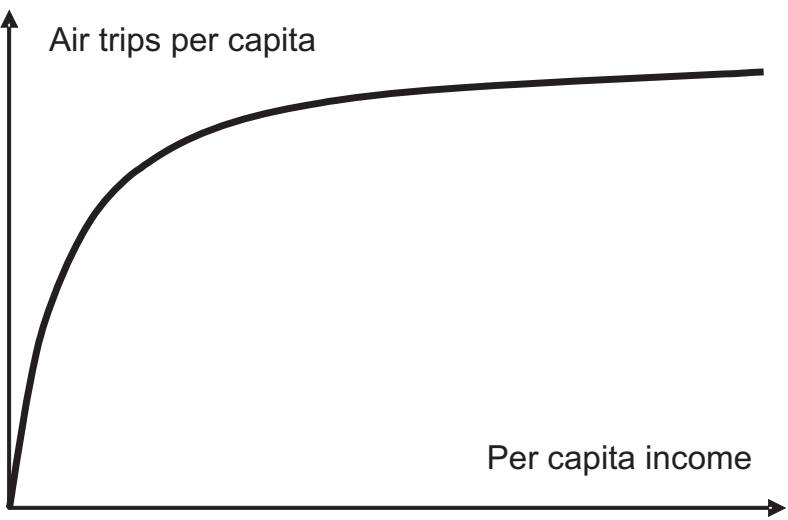

Fig. 3: Relationship between wealth and air traffic

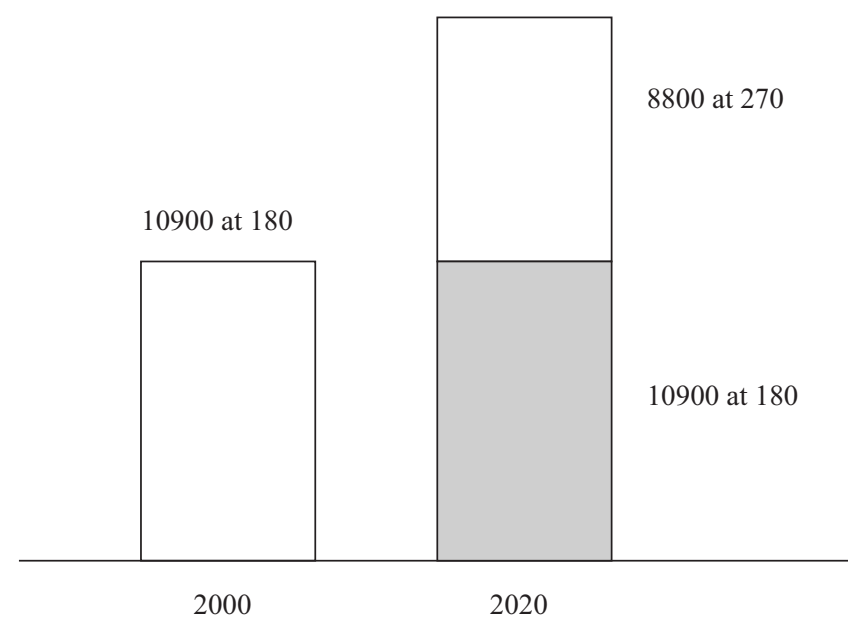

Fig. 4: Evolution of fleet and average size of jet airliners. The grey area accounts for aging jets remaining, jets recycled and jets required for fleet replacement. The white area above represents fleet growth. Overall, around 16000 passenger transport airplanes will be built between 2000 and 2020 required to cope with the increasing demand will be close to 270 seats, as depicted in Fig. 4 [8].

On the other hand, the changes in the geopolitical scenario are accompanied by changes in the perception of public opinion in the USA and Western Europe, where a strong wave of environment protectionism is putting under pressure and detailed scrutiny all sources of noise and pollution including, needless to say, civil aviation.

In the last two decades aeronautical engineers have responded with larger and more efficient airplanes to the strong requirements for cheaper and more environment-friendly aircraft. But the so-called conventional configuration is approaching an asymptote (see Fig. 5) about the size of the Airbus A380.

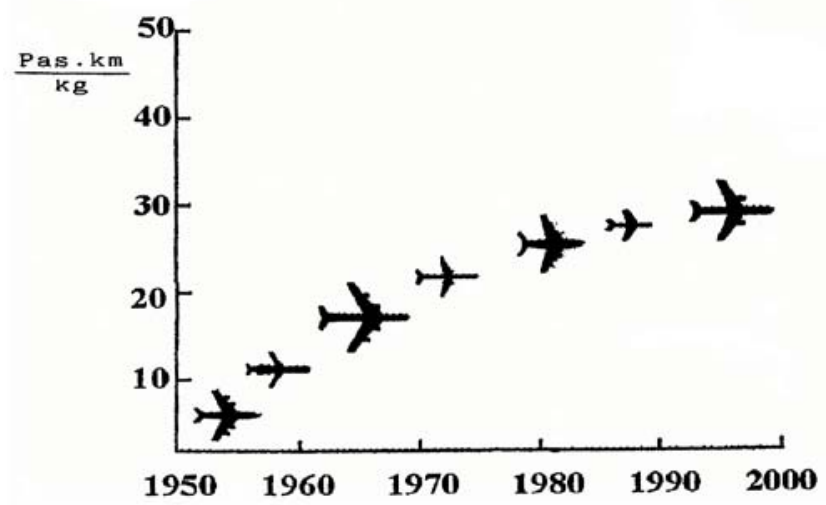

Fig. 5: Evolution of fuel efficiency of jet transport airplanes

Therefore aeronautical engineers have started to consider unconventional aircraft in order to overcome the limits and to achieve performance or operational improvements, including drag reduction, increased useful load, diminishing environmental impact, etc. The arrangements studied are both strange and creative [9-12], as shown in Fig. 6.
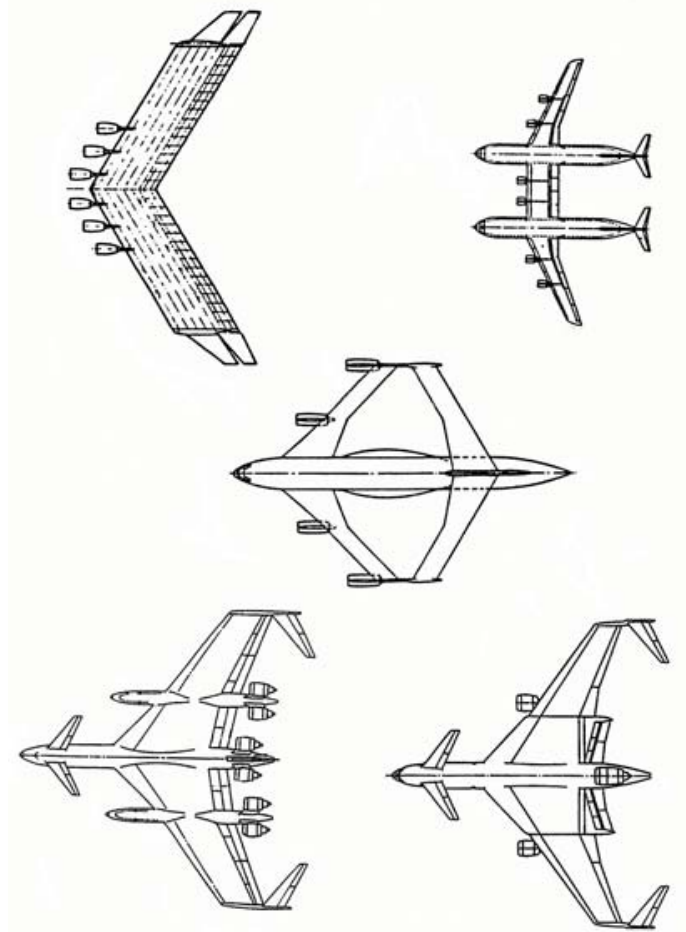

Fig. 6: Unconventional configurations studied for future transport airplanes 
Within this market and technology framework, one of the most promising configurations is the flying wing in its different concepts: blended-wing-body, C-wing, tail-less aircraft, etc. It may provide significant fuel savings and, hence, a lower level of pollution. Moreover, the engines are located above the wing and the aircraft does not need high lift devices in a low-speed configuration, which results in a quieter airplane. This explains the great deal of activity carried out by the aircraft industry and by numerous researchers throughout the world to perform conceptual design level studies, to address the problems and challenges posed by this layout.

This paper discusses the main features of flying wings and blended wing bodies, their advantages over conventional competitors, and some key operational issues, such as airport operation, evacuation, and vortex wake intensity.

\section{The arrangement of flying wings and blended wing bodies}

The flying wing concept is not new. It was used by Lippisch and Horten in Germany in the 1930s and by Northrop on prototypes flown in the 1940s [13], as presented in Fig. 7. Some British firms performed interesting conceptual design work during the 1950 s on potential airliners with this configuration (see Fig. 8) [14].

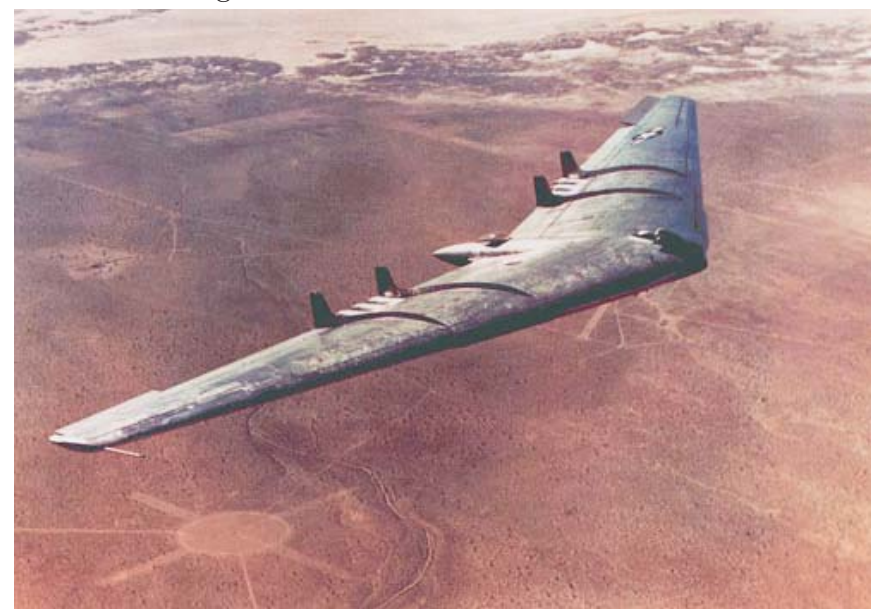

Fig. 7: Northrop YB49 flying wing

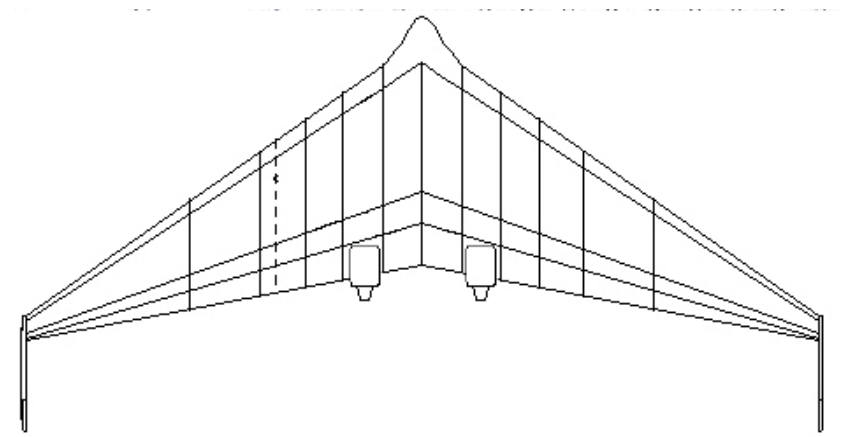

Fig. 9: Plan view sketch of a 300-seat flying wing

Currently, researchers and designers are working on two main configurations: a rather pure flying wing, FW, with straight leading and trailing edges (depicted in Fig. 9); and a blended wing-body arrangement, $\mathrm{BWB}$, in which the body adopts the shape of a much flattened fuselage mated to an outer wing (see Fig. 10).

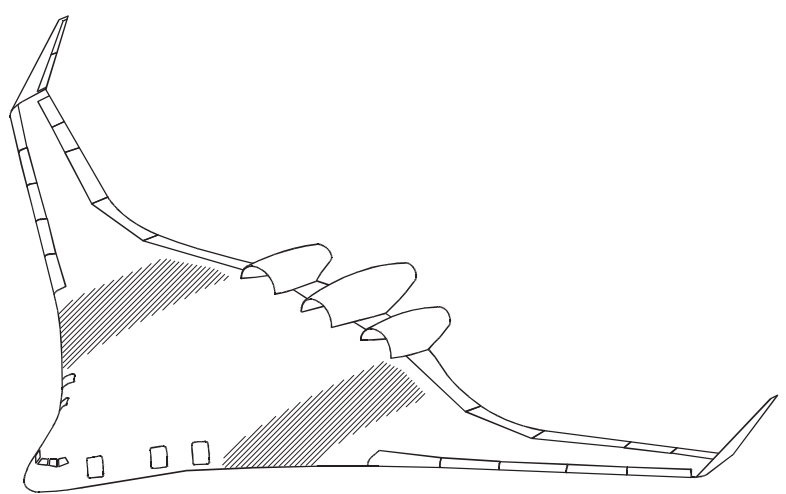

Fig. 10: Sketch of the blended-wing-body aircraft

The studies published cover most existing segments of commercial aviation, from a one hundred seat delta wing [15] to gigantic 1500 seat aircraft [10]. The great majority of papers deal with the BWB layout [16-22], mainly due to its growing capability which easily results in a family [23, 24]. It has improved characteristics over conventional layouts, in terns of aerodynamics, due to its relatively reduced wetted

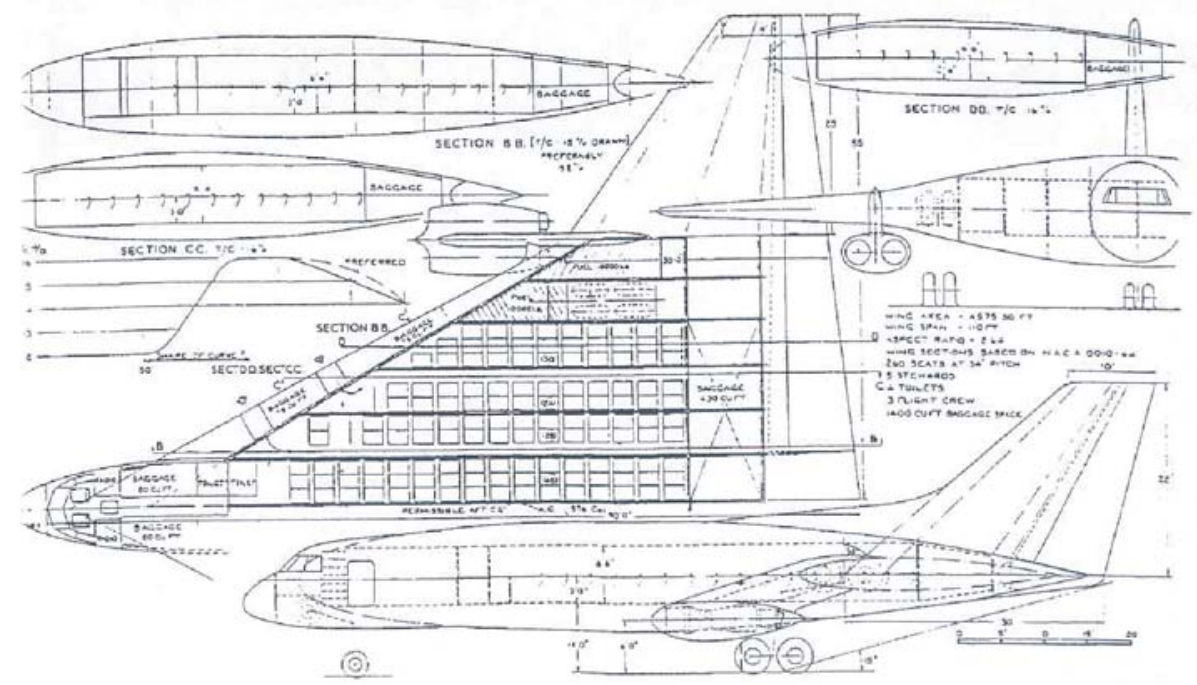

Fig. 8: Sketches of the all-wing Bristol 260 seats 


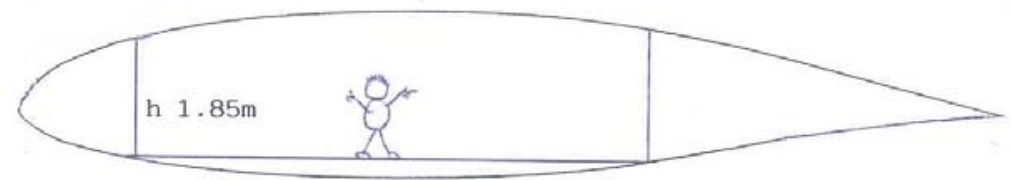

Fig. 11: Habitability inside a flying wing

area, and in terms of structural weight, due to its spanloading effect.

However, the bulky inner body of BWB counter balances, at least in part, these beneficial effects. The lift coefficient is still relatively high [22] and the lift alleviation by payload and main structure is only partial [21]. Pure flying wings behave much better in these two key aspects [25-27]. However, to enable efficient use of the inner space they need to be larger than a minimum size and to incorporate thick airfoils. Moreover, they can hardly form families in a similar sense to what is common with conventional airliners.

In payload-driven design the cabin area, around $1 \mathrm{~m}^{2}$ per passenger in three-class seating, is of extreme importance. The cabin surface, $S_{\mathrm{cab}}$, is linked to the wing geometry as follows:

$\frac{S_{\text {cab }}}{S}=f($ wing planform, inner arrangement,

$$
\text { spar location, } \left.A, \lambda, \frac{t}{c} \ldots\right)
$$

where $S$ is cabin area, $A$ is aspect ratio, $\lambda$ is taper ratio and $t / c$ the relative thickness. It should be recalled that, by definition, $S=b^{2 /} A$.

The wing aspect ratio is ordinarily chosen as a compromise among proper aerodynamic performance, minimum gross weight and suitable area per passenger. Published values are typically around 6 , clearly below those of conventional jets, which fall into the 7-10 range.

Medium-size flying wings pose a crucial problem: habitability, presented in Fig. 11. The torque box of the wing, i.e. the space between the front and rear spars, is pressurised to accommodate the payload. The minimum height in any place of the cabin must be around $1.85 \mathrm{~m}$, which implies either a long chord or a thick airfoil. Large BWB are designed with more than one deck, as in Fig. 12, and habitability issues almost disappear. In contrast, they exhibit a major drag penalty.

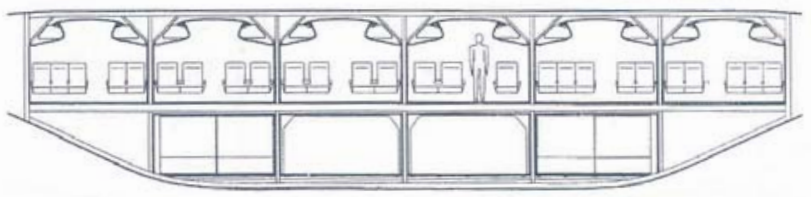

Fig. 12: Cabin and freighthold arrangement in a blended-wing-body aircraft

To avoid very high aerodynamic drag the relative thickness has to be below a certain threshold. Eq. 2 shows the relationship among admissible wing thickness, $t / c$, cruise lift coefficient, $C_{\mathrm{Lcr}}$, cruise Mach number, $M_{\mathrm{cr}}$, and swept angle, $\Lambda$ [28].

$\frac{t}{c}=\left(0.90-0.1 C_{\mathrm{Lcr}}\right)-\left(M_{\mathrm{cr}}+0.02\right) \cos ^{0.5} \Lambda$.
In the former equation the drag rise is assumed to occur at two cents above the cruise Mach number. With appropriate values of intervening variables many $\mathrm{FW}$ and $\mathrm{BWB}$ designs consider 17 percent thick airfoils in their studies.

\section{Architecture of the flying wing}

From the structural point of view, flying wings are arranged as dual entities: an unconventional inner wing with a pressurised torque-box between the spars, for passenger cabins and holds; and an outer wing with fairly conventional architecture, including fuel tanks outboard of the cargo holds.

As the payload is located, completely or in part, inside the wing or inside a lifting shape, the structure around the payload must resist pressurization loads added to ordinary bending and torque induced by the overall configuration. The loads combine in a nonlinear manner and, under extreme manoeuvres or gusts, produce high stresses and severe deformation. The stress level has to be analyzed in terms of fail-safe and damage-tolerance. Significant deformations may in additions affect the operation of the flight controls and equipment, the habitability of the cabin and the aerodynamics of the external shape [29, 30].

Two main concepts have been studied for to enable skin of these aircraft to resist all prescribed loads: a flat sandwich shell and a double-skin vaulted shell. Fig. 13 sketches such concepts. In both cases the resisting shells are helped by large ribs, in order to carry on the concentrated shear forces, to maintain the external aerodynamic shape and to contribute to torsion stiffness. From the point of view of the passengers, there is no major difference, since headroom and passages are optimized to become almost equal. Structurally, however, there are major differences.

In the thick flat sandwich shell, the skin has to be sized to withstand all loads: pressurization, bending and torque; but
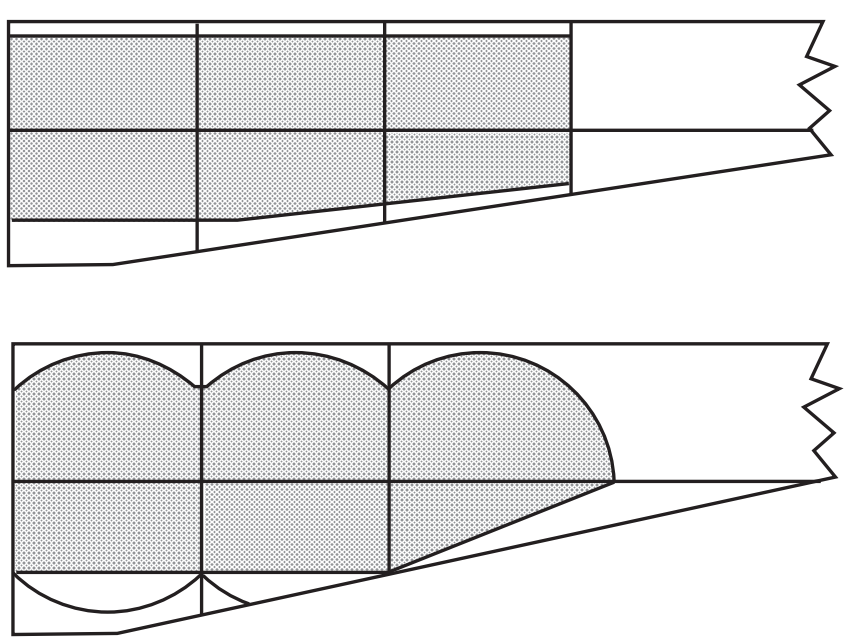

Fig. 13: Alternative structural solutions for the cabin area in flying wings 
its geometry is essentially the same as in conventional wings, i.e. a nearly flat skin stiffened with stringers and held by ribs. On the other hand, the external shape of the wing skin corresponds to the airfoil that is selected. In all cases the upper and lower skins are formed by quasi-planar panels. Resisting the internal pressure with these planar panels is very inefficient $[29,31]$, and thus this solution may lead to undesirable extra weight.

Conversely, the double skin vaulted solution divides the load carrying responsibility into two major components: side-by-side inner cylindrical segments, similar to narrow-body sections, to resist pressurization; and a conventional outer skin to bear the additional loads. The ribs are very large and provide load distributing paths and a joint inner to outer skin. Some researchers indicate that this solution is lighter and also superior due to its load diffusion and fail-safe features [24, 30, 32]. Such a construction is also claimed to be well suited to prevent fatigue crack propagation and to increase buckling rigidity. However, other designers argue that if a rupture occurs in the inner vaulted skin the cabin pressure would have to be borne by the outer skin which, therefore, has to be sized to carry that load too [21]. Obviously this would imply a great deal of extra weight. As an additional point in this controversy, let us recall that common fuselage structures are sized to resist quite large ruptures; up to $1.86 \mathrm{~m}^{2}$ (20 sq ft) according to FAR-JAR 25.365 [33, 34]. Consequently, if the inner vaulted skin takes equivalent responsibility as the fuselage structure in conventional airplanes, the rupture or pressurization loss becomes of secondary importance. Moreover, the available space between the skins may be used to accommodate various items of equipment as will be mentioned later.

Selecting one of these two structural solutions is an open issue, and the critical decision on it affects manufacturing, wiring and maintenance, among other relevant aspects. No estimations exist yet on the influence of such concepts on direct operating costs, and it is not easy to speculate about the possible pre-eminence of one of them. The decision will likely depend on the size and number of decks of each aircraft.

Independently of the chosen solution for the skin, the best cabin arrangement seems to be a set of parallel bays, slightly

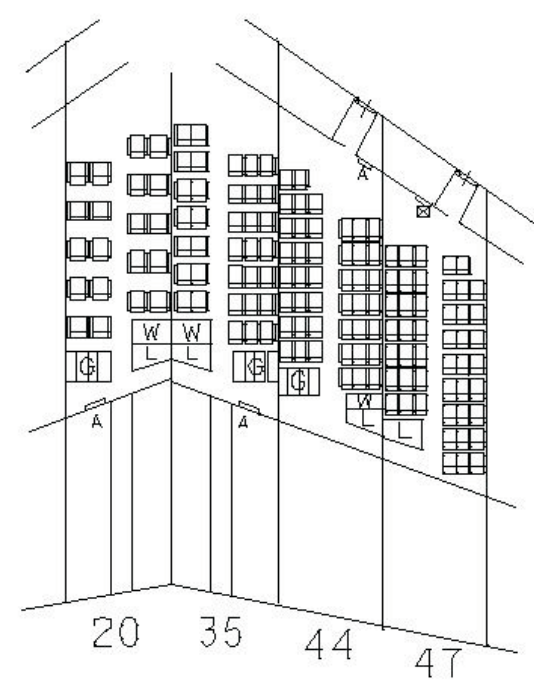

Fig. 14: Three-class seating in a flying wing. The two outer bays are symmetrical shifted longitudinally following the wing's sweptback (see Fig. 14). Once this concept is established the best layout to maximize the number of passengers abreast with the minimum width is a 3-by-3 disposition, since it requires only one aisle per bay. This means a narrow body-like size. The cabin width of the current Boeing narrow body fuselages is $3.53 \mathrm{~m}$ and the analogous figure for Airbus is $3.70 \mathrm{~m}$. This last must be considered a minimum, since FW and BWB are designed to fly much longer ranges than any A320 or B737 and, therefore, should offer roomer cabins. Such an arrangement provides enough flexibility for three-class seating [24, 27], as shown in Fig. 14, corresponding to a 300-seat class FW. In larger aircraft there can be more bays, the bays may be more stretched and the overall capacity can easily reach 800-1000 passengers [21, 23, 24].

First class and business travellers occupy the central bays to benefit from improved comfort levels in rough flights, although recent investigations indicate that unpleasant rolling accelerations could be counterbalanced by smoothed manoeuvres and multimedia equipment [35].

Needless to say, these aircraft comply with suitable standards concerning access, evacuation and on board services. The doors must be arranged to allow passengers to board and leave the aircraft independently of galley servicing and cleaning. Furthermore they have to be equipped with ramp slides, provisions for ditching, etc. Several symmetrical couples of type A doors are located on the sides of the front corridor, through the front spar and leading edge, and some symmetrical pairs are located at the rear, through the second spar and trailing edge. In some conceptual designs all galleys, toilets and wardrobes are located at the rear of the cabin for aesthetic and operational reasons. This arrangement of exits and services is very efficient and improves emergency evacuation.

As in any other airliner, on board services include galleys (one area per 100-120 passengers), toilets (one per 40-50 passengers), overhead lockers for passengers' light baggage, stowage for mail, duty-free items or passengers' coats, new in-flight services, etc [36].

These roomy aircraft have few problems with accommodating all equipment and installations required on board: electrical, air conditioning, emergency oxygen, avionics, fuel tanks, de-icing and anti-icing, auxiliary power units, etc. For example, the non-pressurized leading and trailing edges provide precious spaces close to the cabin bays as does the space between the inner and outer skins in the double vaulted shell architectural solution.

\section{Advantages of the flying wing}

One of the claimed advantages of flying wings is weight saving, in terms of both maximum take-off weight, MTOW, and trip fuel, TF. These and other main weights can be estimated at conceptual design level as follows. By definition, the maximum take-off weight to perform a specified mission is

$$
M T O W=O E W+P L+T F+R F
$$

where $O E W$ is the operating empty weight, obtained from an empirical correlation between $O E W$ on one side, and $M T O W$ and wing size on the other side, analogous to the procedure described in [37] for $O E W, M T O W$ and fuselage size; $P L$ stands for payload; $T F$ represents the fuel burnt during the 
flight and $R F$ the reserve fuel. Both this last named and the consumption in take-off, climb, descent and landing can be considered as known fractions of the actual weight in each phase [38]. The fuel burnt in cruise, $W_{\mathrm{fcr}}$, is computed using the Breguet range equation [28, 37, 38]

$$
R=K \ln \frac{W_{\mathrm{i}}}{W_{\mathrm{i}}-W_{\mathrm{fcr}}},
$$

where $R$ is range, $W_{\mathrm{i}}$ the initial weight in the cruise phase, and $K$ a range parameter assumed constant and defined as

$$
K=\frac{V}{c_{\mathrm{j}}} \frac{L}{D} .
$$

Eq. 5 shows how the range parameter incorporates the influence of cruise speed, $V$, the specific fuel consumption, $c_{\mathrm{j}}$, and the average lift over drag ratio in cruise, $L / D$.

The average lift over drag ratio of a jet airliner in cruise is about 92 to 95 percent of the maximum [37]. This last can be expressed as

$$
\left(\frac{L}{D}\right)_{\max }=\sqrt{\frac{\pi A \varphi}{4 c_{\mathrm{f}}}} \sqrt{\frac{S}{S_{\mathrm{wet}}}},
$$

where $c_{\mathrm{f}}$ is the average friction coefficient (mainly dependent on the Reynolds number) over the exposed area, $S_{\text {wet }}$. Since flying wings have a lower aspect ratio but also a lower friction coefficient (due to its larger chord and, hence, larger Reynolds number) [37] the key point is the smaller relative exposed area. This is easily observed in Fig. 15.

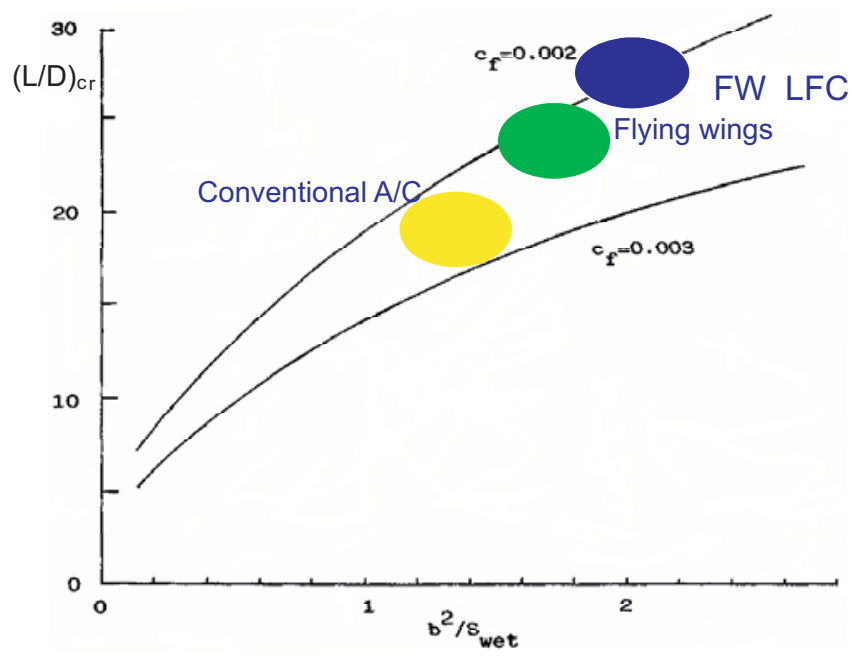

Fig. 15: Lift over drag ratio and aerodynamics of various types of aircraft

So the lift over drag ratio of flying wings in cruise is about 20-25 percent larger than for jet transports. Eq. 6 includes the product $\pi A \varphi$ that comes from the non-lift dependent part of the drag polar, as explicit in Eq. 7.

$$
C_{\mathrm{D}}=C_{\mathrm{D} 0}+\frac{C_{\mathrm{L}}^{2}}{\pi A \varphi} .
$$

Quantifying these effects, most databases suggest $C_{\mathrm{D} 0}$ values in the range of 0.014-0-020 for common jets [28, 37, 38-40] but fall to $0.008-0-010$ in flying wings and similar concepts. This means cruise $L / D$ around 23-25 [21, 26, 27], slightly above 20 percent over current jets. If laminar flow control (LFC) can be introduced over part of the exposed area [41-43] the non-lift dependent term decreases up to 0.007-0.008 with $L / D$ almost reaching 30 [27].

An uncommon characteristic of flying wings is that they have to cruise at higher altitudes than conventional jets, between 41000 and $47000 \mathrm{ft}$ in the various steps of long flights. This fact deserves some explanation. The lift coefficient for maximum range must be [44]

$$
C_{\mathrm{Lcr}}=\sqrt{\beta C_{\mathrm{D} 0} \pi A \varphi}
$$

where $\beta$ is a parameter related to the Mach number dependence of the specific fuel consumption [44]. For current high by pass ratio turbofans it is about 0.6 . This results in $C_{\mathrm{Lcr}}$ around 0.5 for conventional airliners and some 0.3 for flying wings.

In cruise, lift must balance weight; i.e.

$$
W_{\mathrm{cr}}=L=\frac{\gamma}{2} p_{\mathrm{cr}} M_{\mathrm{cr}}^{2} C_{\mathrm{Lcr}} S,
$$

where $\gamma$ is 1.4 , and $p_{\text {cr }}$ and $M_{\text {cr }}$ are the pressure and Mach number at cruise conditions, respectively. Eqs. 8 and 9 can be rearranged as follows:

$$
p_{\mathrm{cr}}=\frac{2}{\gamma} \frac{W_{\mathrm{cr}} / S}{M_{\mathrm{cr}}^{2} \sqrt{\beta C_{\mathrm{D} 0} \pi A \varphi}}
$$

Flying wings are foreseen with cruise wing loading around 2000-3000 Pa, instead of 4000-6000 Pa of conventional airliners. So, with the same Mach number, lower $C_{\mathrm{D} 0}$ and much lower wing loading than conventional airliners, the flying wing must fly at a higher altitude (as indicated in Fig. 16) to benefit from its intrinsic design features.

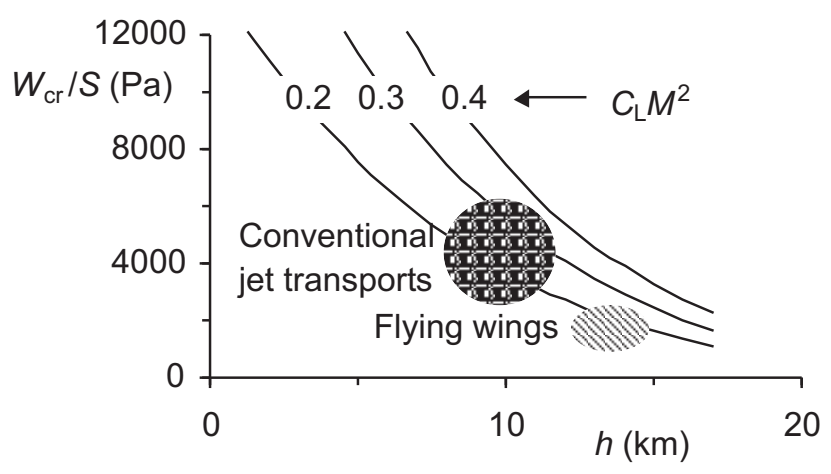

Fig. 16: Relationship between wing loading and cruise altitude

The engines are sized following four common requirements [37-40]: cruise capability, take-off field length, landing field length and second segment climb. A suitable design value for thrust over weight ratio is $T_{\mathrm{to}} / W_{\mathrm{to}}=0.25$, which includes an allowance for the thrust lapse from static take-off to high subsonic, high altitude cruise conditions. Interestingly most designs do not consider high lift devices for field manoeuvres, due to the relatively low wing loading of flying wings.

Closely related to the very good aerodynamics just mentioned, the specific range, i.e. the distance flown per unit fuel mass burnt, is defined as

$$
\frac{\mathrm{d} R}{\mathrm{~d} W}=-\frac{V}{c_{\mathrm{j}}} \frac{L}{D} \frac{1}{W} .
$$



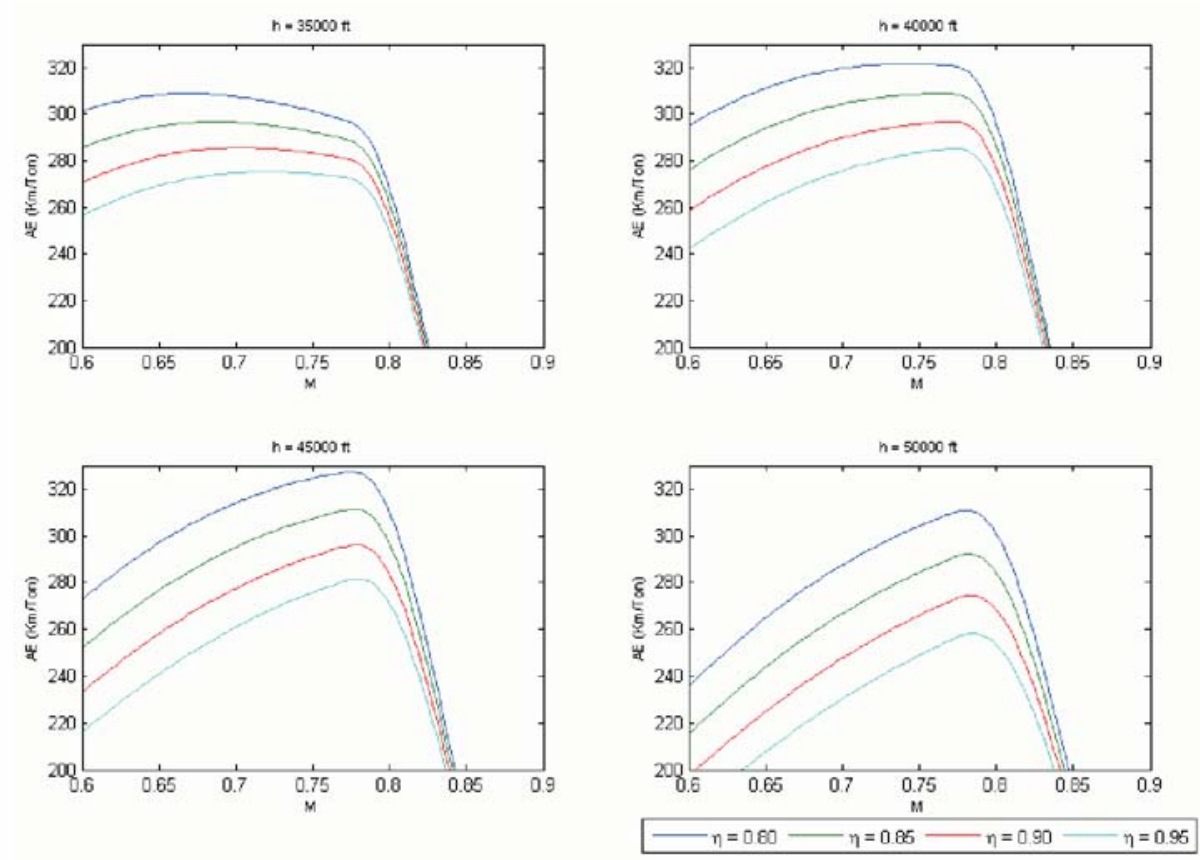

Fig. 17: Specific range for a 300-seat flying wing, designed at $M_{\text {nom }}=0.8$, in terms of actual cruise Mach number, cruise altitude and relative weight to $M T O W$

For a given aircraft the specific range can also be expressed as a function of the flight conditions, according to Eq. 12

$$
\frac{\mathrm{d} R}{\mathrm{~d} W}=f(M, h, \eta),
$$

where $\eta$ is the relative weight with respect to MTOW.

Fig. 17 presents the specific range for a 300-seat class flying wing. The results show that the optimum altitude for the maximum range of this precise flying wing is around $45000 \mathrm{ft}$, as already indicated. This maximum, as a function of altitude, is rather flat; which means that the loss of range is almost negligible provided the flight remains between 41000 and $47000 \mathrm{ft}$. The sharp decline seen on the right hand side of the plots is due to a sudden risen subsonic drag.

Estimating the fuel consumption in the short duration phases of the flight (take-off, landing, etc) and integrating the specific range over the duration of the mission yields the payload-range diagram. A two - or three step - cruise is commonly defined in long flights to match altitude with decreasing wing loading. Fig. 18 presents the PL-R diagram of the 300-seat class aircraft mentioned above. Although not fully optimized, it may be close to future practice of FW operation. In the case of LFC, a hypothesis has been introduced. To be conservative in the PL-R estimation it is assumed that the LFC equipment fails completely during the last three hours of flight, in parallel to the conditions and extra fuel allowances required for current ETOPS (Extended range Twin OPerations) [45]. Hence Fig. 18 shows three different diagrams: one corresponding to FW without LFC; another with LFC but keeping the same $M T O W$ of the original aircraft (which is not sound since the mission range is not maintained); and another diagram with the same mission specifications but reduced $M T O W$.

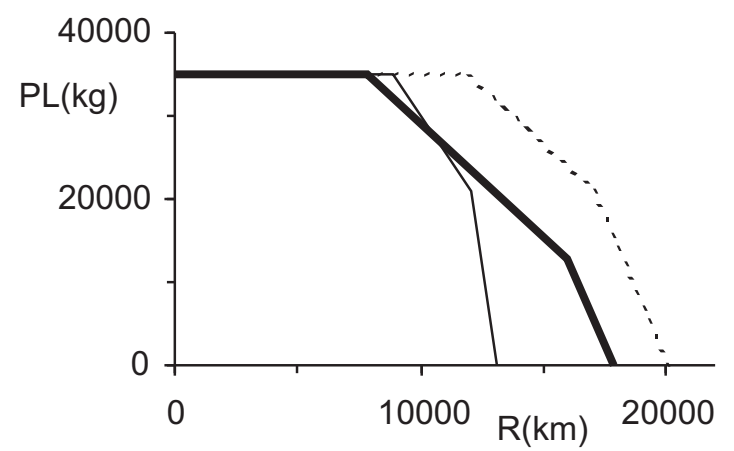

Fig. 18: Payload-range diagram of a flying wing (thin line), an LFC flying wing with the same MTOW as "forme concepto" (dashed line), and an LFC flying wing with the same mission range

Obviously the payload-range diagram is a boundary of all possible routes. The utilization of a given airplane is quite different in distinct companies. Thus, Fig. 19 depicts a histogram of routes flown with A340-300. The dual mode is characteristic of current practice by airlines: they use the aircraft in many medium-to-long range stages, as well as in some dense, short steps to increase annual utilization and profits [46]. FW show greater operational flexibility for exhibiting lower empty weight and much lower fuel consumption, thus making route planning easier and more efficient.

Taking all fuel burnt during the flight of an LFC flying wing, the resulting consumption is $14.6 \mathrm{~g} / \mathrm{pax} . \mathrm{km}$ or 1.82 1/pax.100km, somewhat lower than the Airbus A380 [47] and comparable to the consumption of fully occupied efficient cars [27].

Table 1 collects the main performances of flying wings and common airliners of the 300-seat class. It shows the great advantages of flying wings both in fuel efficiency and in take-off and landing field lengths. 


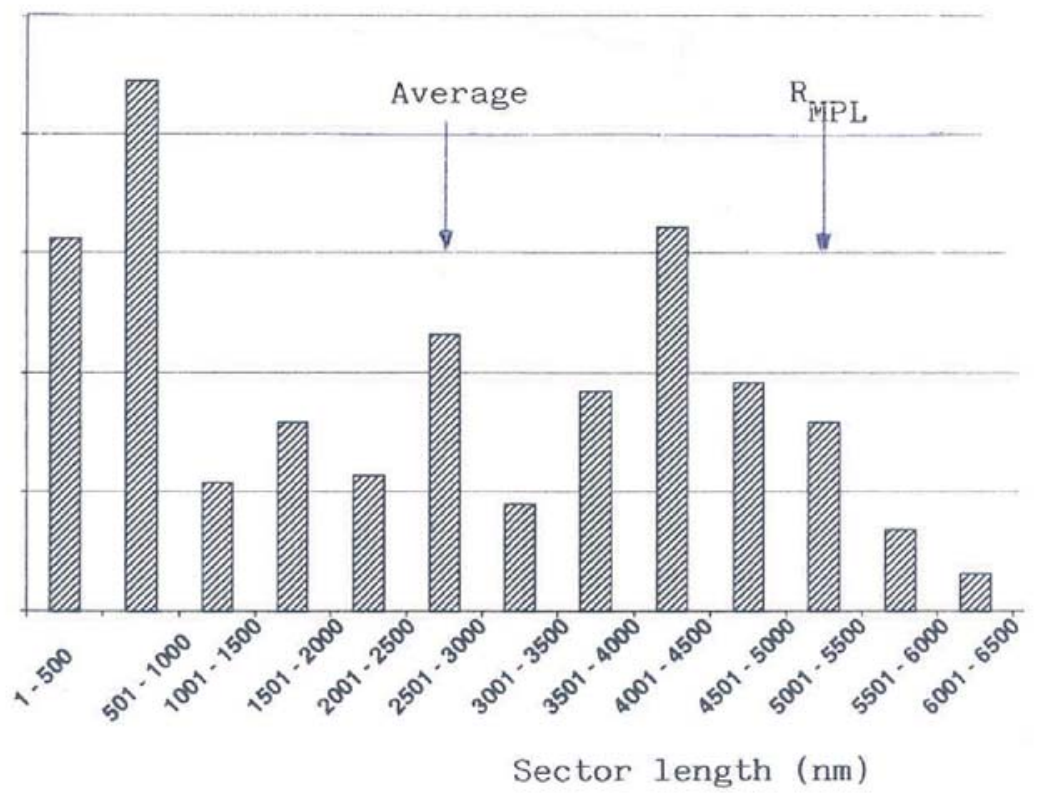

Fig. 19: Worldwide utilisation histogram of the A340-300

Table 1: Summary of field and trip performances of flying wings and conventional airliners

\begin{tabular}{|l|c|c|c|c|}
\cline { 2 - 5 } \multicolumn{1}{c|}{} & A330-200 & B777-200 & Flying wing & LFC FW \\
\hline$S_{\text {tofl }}(\mathrm{m})$ & 2390 & 2310 & 1860 & 1930 \\
\hline$S_{\text {lfl }}(\mathrm{m})$ & 1600 & 1550 & 1320 & 1350 \\
\hline $\begin{array}{l}\text { Fuel eff. } \\
\text { (g/pax.km) }\end{array}$ & 21.5 & 23.5 & 19.8 & 14.6 \\
\hline
\end{tabular}

\section{Some operational aspects of the flying wing}

This section is devoted to three meaningful aspects of airplane operation: on-ground manoeuvres and servicing, emergency evacuation, and vortex wake effects.

No major differences are found when studying runway/taxiway movements or airport terminal operations of

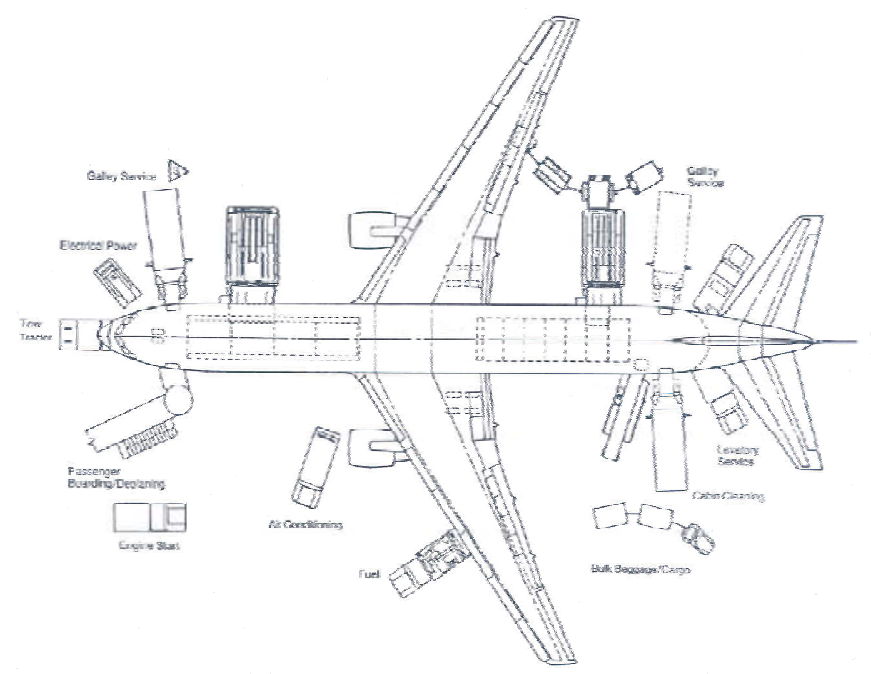

Fig. 20: On ground servicing of the B767-200 unconventional aircraft, such as flying wings or blended-wing-bodies, provided they fit within the newly defined $80 \mathrm{~m}$ box and the landing gear track is smaller than or equal to $14 \mathrm{~m}$ [48]. These limits are very restrictive for large BWB, frequently designed with a wingspan greater than $100 \mathrm{~m}$ and landing gear track near $20 \mathrm{~m}$. It should be noted that all major airports have already made major modifications to accommodate the A380 and other potential ultra high capacity airplanes [49], and no further major works can be justified in the mid-term future.

With respect to servicing unconventional airplanes, there are no relevant issues that could delay or pose serious difficulties to their entry into service. As a basis for comparison Fig. 20 shows the busy on-ground servicing of a conventional medium-size airplane, the B767, with many vehicles around the aircraft to enable a complete turn-around in about 45 minutes.

In the case of a medium size flying wing belonging to the 300-seat class, presented in Figs. 9 and 14, the rear doors can be installed through the rear spar and trailing edges. They are used for cabin cleaning and galley servicing. In this situation passenger services, cargo/baggage handling and airplane servicing can be done simultaneously with the usual overlap of activities, as shown in Fig. 21. Interestingly, the loading and unloading of passengers in airport piers requires the finger's floor to be positioned about $5 \mathrm{~m}$ above the ground for medium-size wide bodies, but at a moderate height of around $3 \mathrm{~m}$ through the leading edge of the flying wing. Container loading is also performed in the front part, but at a distance from the passenger doors. The doors of the cargo compartments are at similar height, around $2.5-3.0 \mathrm{~m}$, in all cases. Waste draining is performed below the central part of the wing and fuel refilling is carried out below the outer part of the wing. It is evident that the situations in Figs. 20 and 21 are very similar.

Emergency evacuation is another issue in the future operation of any aircraft. It is always a major issue, particularly in large airplanes or when the configuration is unusual. Very lit- 


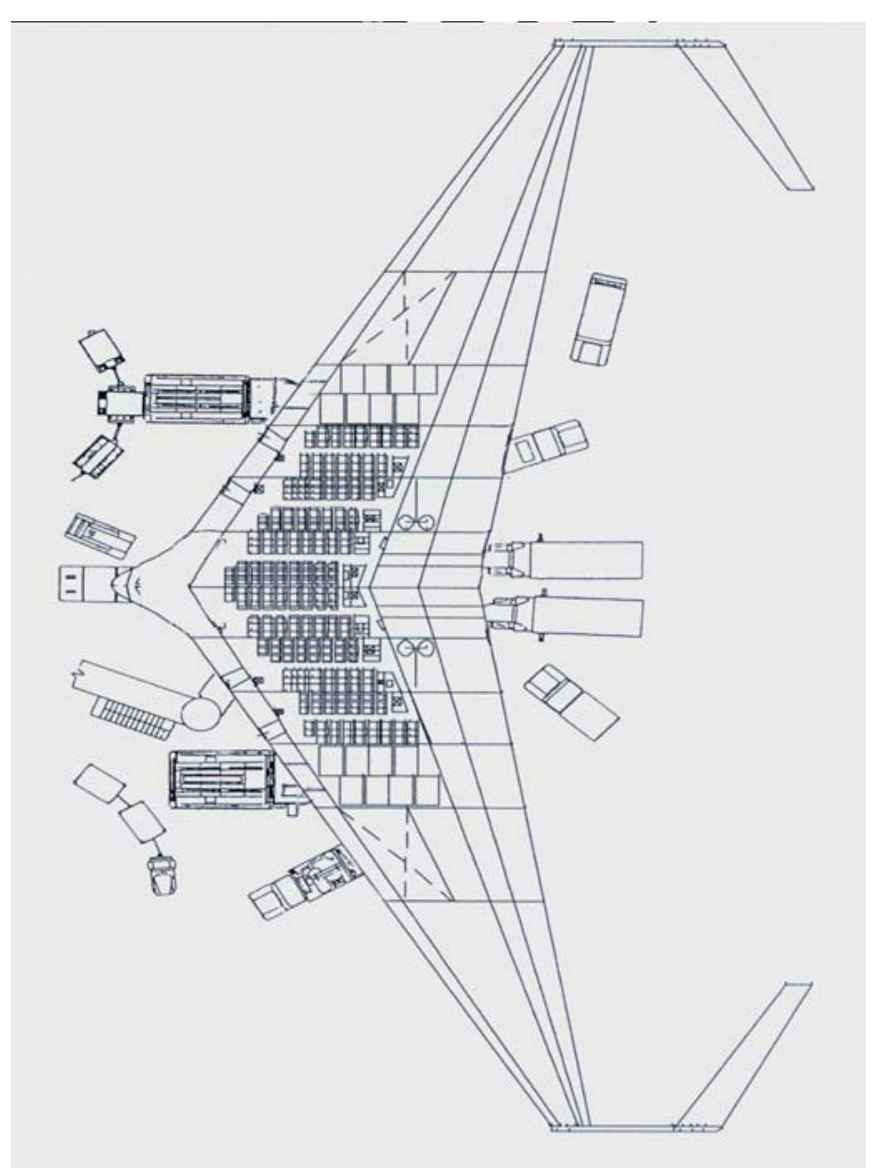

Fig. 21: On ground servicing of a 300 seat flying wing

tle has been published about this point on flying wings. The only aspect frequently included in conceptual design drawings is that the doors/exits are located in the leading edge. This location entails many problems, such as the need for structural reinforcements to assure integrity in crashes or object strikes, or provisions to avoid cabin flooding after ditching. Exits through the trailing edge pose fewer problems, but they require a great deal of engineering imagination.

To improve survivability after crashes, emergency landings, etc, the airworthiness authorities require manufacturers and operators to meet a number of design and performance standards related to cabin evacuation. One of the most important regulations, albeit controversial, is the 90-second rule, which requires a demonstration in any new or derivative type airplane that all passengers and crew members can safely abandon the aircraft in less than 90 seconds, with half of the usable exits blocked, minimum illumination provided by floor lighting, and a certain age-gender mix in the simulated occupants [33, 34].

The only objective of the demonstration is to show that the airplane can be evacuated in less than 90 seconds under the aforementioned conditions. Therefore, it only provides a benchmark for consistent evaluation. It cannot represent accident scenarios, nor is intended for system optimization.

Since demonstrations are costly and dangerous, various computer models have been developed by the airworthiness authorities, airplane manufacturers and independent researchers to gain insight into and understanding of the evacuation process. However, all models have significant limi- tations. The results reported here are obtained with a seat-to-exit assignment algorithm that can be combined with various rules to minimize the total distance travelled by all passengers along their escape trajectories [50].

Fig. 22 shows the suitable evacuation routes and the connections among various areas in the 300 -seat class flying wing considered in this paper [27]. The innermost bay has no front

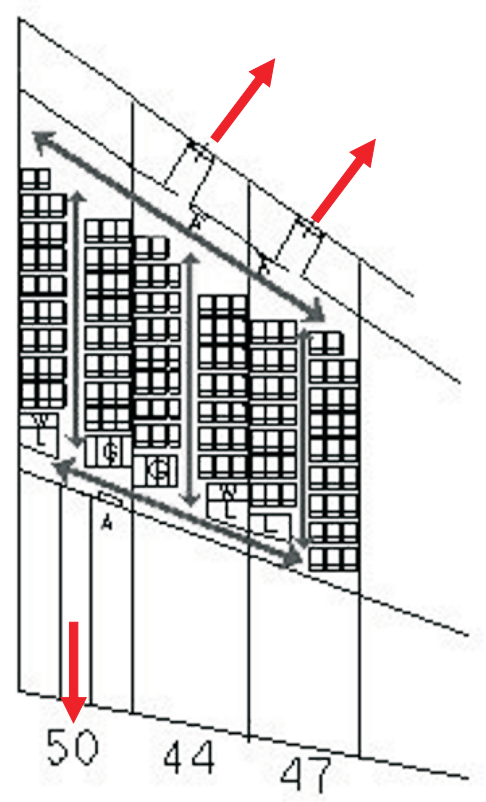

Fig. 22: Evacuation corridors and exits of a flying wing

door since the leading edge there is distorted by the nose bullet cockpit. According to the rules, only half of the exits can be used in the 90 -second trials. Several scenarios have been analysed. The worst results correspond to the case where the usable exits are the two front doors on one side of the plane of symmetry, and the rear door on the other side. Table 2 summarises the results of the evacuation analysis in this condition and shows a fairly unbalanced situation. In this case the average distances are acceptable, but the maximum distance appears rather long for a passenger escaping through the rear exit. Moreover, the outermost front door seems to be empty in comparison to others, but in a real trial some of the passengers approaching the inner front door would escape through the nearby empty door, since there would be no queue most of the time. These results closely resemble those of airplanes with a slightly higher capacity, like the A340-300, DC10-30 or L1011-200 [50]. Therefore the flying wing configuration suffers a certain penalty for the extra wide cabin layout, but without posing any remarkable problem in terms of passenger flow rate or total evacuation time.

Table 2: Evacuation results of a 300-seat flying wing

\begin{tabular}{|l|c|c|c|}
\cline { 2 - 4 } \multicolumn{1}{c|}{} & $\mathrm{N}^{\circ}$ of evacuees & $\mathrm{X}_{\text {mean }}(\mathrm{m})$ & $\mathrm{X}_{\max }(\mathrm{m})$ \\
\hline Outer front exit & 54 & 5.3 & 8.9 \\
\hline Inner front exit & 132 & 6.3 & 10.3 \\
\hline Rear exit & 138 & 10.7 & 18.5 \\
\hline
\end{tabular}


Table 3: ICAO aircraft separation rules. For all combinations not, shown the minimum $3 \mathrm{~nm}$ or $79 \mathrm{~s}$ applies

\begin{tabular}{|l|c|c|c|}
\hline Leader aircraft $($ MTOW $)$ & Follower aircraft & Separation (nautical miles) & $\begin{array}{c}\text { Time delay (s) } \\
(\mathrm{V}=70 \mathrm{~m} / \mathrm{s})\end{array}$ \\
\hline Heavy $(>136000 \mathrm{~kg})$ & Heavy & 4 & 106 \\
\hline Heavy & Medium & 6 & 132 \\
\hline Heavy & Light & 5 & 159 \\
\hline Medium $(<136000 \mathrm{~kg})(>7000 \mathrm{~kg})$ & Light & 6 & 132 \\
\hline
\end{tabular}

Regarding the third topic, all airplanes in flight produce an intense wake, mainly characterized by a pair of counter-rotating vortices, originating at the wing tips. The wake thus formed is very severe, with induced velocities higher than those found in natural atmospheric turbulence. This phenomenon obliges a certain time and distance separation to be mentioned between aircraft in take-off and landing manoeuvres, imposing a limit on the number of movements per runway. Table 3 indicates aircraft separation in the terminal area in a low-speed configuration [51].

The initial circulation of the aircraft wake, 0 , is practically maintained over a very long distance downstream. It can be computed under the hypothesis of an elliptic spanwise lift distribution as

$$
\Gamma_{0}=\frac{4 W}{\pi \rho V b},
$$

where $W$ is weight (equal to lift), $V$ speed, $b$ wingspan and $\rho$ air density.

Following the Hallock-Burnham model [51, 52], one of the most realistic for describing the evolution of the vortex wake, the maximum tangential velocity is achieved at the radius of the vortex core. This radius enlarges downstream by diffusion and, hence, the maximum tangential velocity decays approximately as indicated by the following expression:

$$
v_{\theta \max }=\frac{\Gamma_{0}}{4 \pi r_{c}}=\frac{20}{\pi} \sqrt{\frac{V \Gamma_{0}}{x}},
$$

where $r_{\mathrm{C}}$ is core radius, and $x$ the distance downstream.

Fig. 23 represents the evolution of the maximum tangential velocity for an A330, a B777 and a 300-seat flying wing

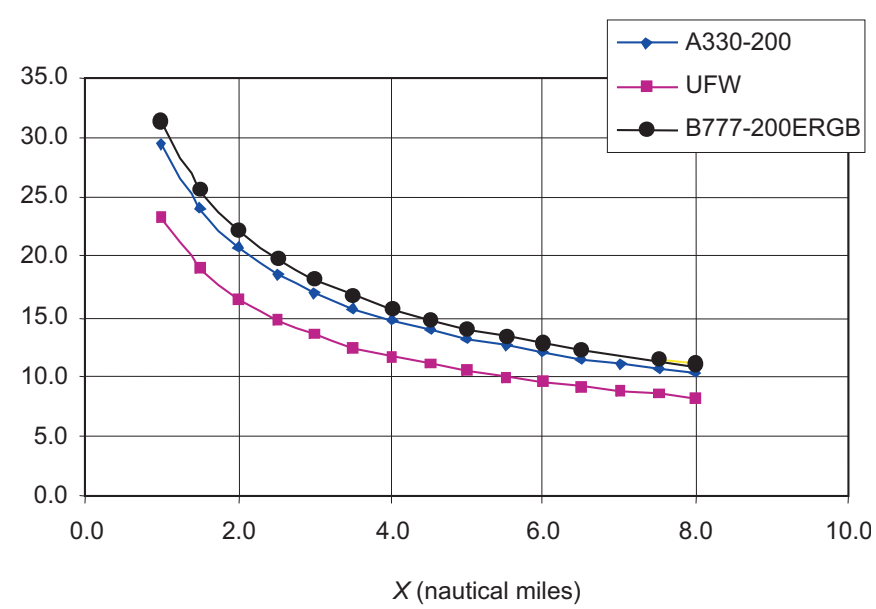

Fig. 23: Downstream evolution of the maximum tangential speed (in metres per second) in the wake produced by a flying wing at take-off
[53] in take-off. The relative positions are exactly the same in landing. The B777 always exhibits the most intense wake, and the FW300 the least powerful vortices. The results show that the flying wing, which due to its weight belongs to the heavy aircraft category ( $W>136000 \mathrm{~kg}$ in Table 3$)$, could be considered within the medium category in terms of airport operations; i.e. time and distance separation, and this could increase the number of operations at airports.

\section{Conclusions}

The flying wing, in its different arrangements, is one of the most promising and efficient configurations envisaged to face the increasing demand for air traffic and attenuate the impact produced by so many aircraft operations. This configuration, already studied in the 1930s and 1940s, is presently receiving a great deal of attention because of its potential advantages over conventional competitors in field, its cruise performances and its greater environment-friendliness.

Current interest focuses on the so-called blended-wing-body layout, in which the fuselage is substituted by a much flattened body that coalesces with a conventional outer wing, and a rather pure flying wing, with straight leading and trailing edges. Not only very large but also medium-size aircraft, similar in passenger capacity to common wide bodies, exhibit a remarkable improvement over conventional airplanes in field and cruise performance, as well as in emissions and noise. The flying wing configuration may better exploit emerging technologies such as laminar flow control, vectored thrust or active stability, taking even these advantages even further.

There are also many open issues: the structural arrangement around the cabin; emergency evacuation; large size effects (beyond the $80 \mathrm{~m}$ box or the $14 \mathrm{~m}$ lading gear track); passenger acceptance of an uncommon cabin layout; vertical accelerations in gusty weather or roll manoeuvres; etc.

Taking into account the very positive results published by many researchers all over the world, and the level of difficulty of the still open questions, the flying wing could become a new paradigm for commercial aviation and could enter into service within the next decade.

\section{Acknowledgment}

A version of this paper was presented as a Plenary Lecture at the AED2006 Conference, held in Prague in June 2006. The author feels honoured by the invitation to contribute to this Conference and expresses his sincere acknowledgment to the Organising Committee. The written version was finished at Toulouse, France, during a sabbatical year hosted 
by SupAero. The financial support of Universidad Politecnica de Madrid and the Spanish Ministry of Education for this research and sabbatical under grants PR2005-0100 and TRA2004-07220 is highly appreciated.

\section{References}

[1] Trimble, W. F. (Ed.): From airships to Airbus: the history of civil and commercial aviation. Volume 2: Pioneers and Operations. Washington, USA, Smithsonian Institution, 1995.

[2] Anderson, J. D.: The Airplane. A History of its Technology. Reston (VA), USA, AIAA, 2002.

[3]www.boeing.com/histo ry/boeing/b47.html

[4] Jarrettt, P.: Modern air transport: worldwide air transport from 1945 to the present. London, UK, Putnam, 2000.

[5] Worldwide Airports Traffic. Report 2003. London, UK, Airport Council International, 2003.

[6] Long-term forecast of air traffic 2004-2025. Brussels, B, Eurocontrol, 2005.

[7] Current Market Outlook 2004. Seattle, USA, Boeing Commercial Airplanes, 2004.

[8] Global Market Forecast 2004-2023. Blagnac, F, Airbus, 2005.

[9] Lange, R. H.: Review of Unconventional Aircraft Design Concepts. Journal of Aircraft, Vol. 25 (1988), p. 385-392.

[10] McMasters, J. H., Kroo, I. M.: Advanced configurations for very large transport airplanes. Aircraft Design, Vol. 1 (1998), p. 217-242.

[11] Schmitt, D.: Challenges for unconventional transport aircraft configurations. Air and Space Europe, Vol. 3 (2001), p. 67-72.

[12] Nangia, R., Palmer, M., Tilman, C.: Unconventional high aspect ratio joined-wing aircraft incorporating laminar flow. Applied Aerodynamics Conference, AIAA Paper 2003-3927, 2003.

[13] Pelletier, A.: Les ailes volantes. Boulogne, F, ETAI, 1999.

[14] Payne, R.: Stuck on the Drawing Board. Unbuilt British Commercial Aircraft since 1945. Stroud, UK, Tempus, 2004.

[15] Stinton, D.: The anatomy of the aeroplane. 2nd Ed. Oxford, UK, Blackwell, 1998.

[16] Denisov, V. E., Bolsunovsky, A. L., Buzoverya, N. P., Gurevich, B. I., Shkadov, L. M.: Conceptual Design for Passenger Airplane of Very Large Passenger Capacity in the Flying Wing Layout. Proceedings $20^{\text {th }}$ ICAS Congress, Sorrento, Italy, Vol. II, 1996, p. 1305-1311.

[17] Liebeck, R. H., Page, M. A., Rawdon, B. K.: Blended-Wing-Body Subsonic Commercial Transport. $36^{\text {th }}$ Aerospace Science Meeting E Exhibit, Reno (NV), USA, AIAA Paper 98-0438, 1998.

[18] Bolsunovski, A. L., Buzoverya, N. P., Gurevich, B. I., Denisov, V. E., Dunaevski, A. I., Shkadov, L. M., Sonin, O. V., Udzhukhu, A. J., Zhurihin, J. P.: Flying wing: problems and decisions. Aircraft Design, Vol. 4 (2001), p. 193-219.

[19] Mialon, B., Fol, T. and Bonnaud, C.: Aerodynamic Optimization of Subsonic Flying Wing Configurations. $20^{\text {th }}$ AIAA Applied Aerodynamics Conference, St. Louis (MO), USA, AIAA Paper 2002-2931, 2002.
[20] Cook, M. V., Castro, H. V.: The longitudinal flying qualities of a Blended-Wing-Body civil transport aircraft. Aeronautical Journal, Vol. 108 (2004).

[21] Liebeck, R. H.: Design of the Blended Wing Body Subsonic Transport. Journal of Aircraft, Vol. 41 (2004), p. 10-25.

[22] Qin, N., Vavalle, A., Le Moigne, A., Laban, M., Hackett, K., Weinerfelt, P.: Aerodynamic considerations of blended wing body aircraft. Progress in Aerospace Sciences, Vol. 40 (2004), p. 321-343.

[23] Willcox, K., Wakayama, S.: Simultaneous optimization of a multiple-aircraft family. Journal of Aircraft, Vol. 40 (2003), p. 616-622.

[24] Bradley, K. A.: Sizing Methodology for the Conceptual Design of Blended-Wing-Body Transports. NASA CR 2004-213016, 2004.

[25] ,Martinez-Val R. and Schoep, E.: Flying wing versus conventional transport airplane: the 300 seat case. Proceedings $22^{\text {nd }}$ ICAS Congress, Harrogate, UK, CD-ROM, 2000, paper 113.

[26] Martinez-Val, R., Perez, E.: Medium size flying wings. In Innovative Configurations and Advanced Concepts for Future Civil Aircraft (Eds. E. Torenbeek, H. Deconinck). Rhode-Saint-Gen se, Von Karman Institute, B, 2005.

[27] Martinez-Val, R., Perez, E., Alfaro, P., Perez, J.: Conceptual design of a medium size flying wing. Journal of aerospace Engineering, Part G Proc. IMechE, 221, 2007, p. 57-66.

[28] Howe, D.: Aircraft Conceptual Design Synthesis. London, UK, Professional Engineering Publishing, 2000.

[29] Niu, M. C. -Y.: Airframe Structural Design. $2^{\text {nd }}$ ed. Hong Kong, PRC, Conmilit Press, 1999.

[30] Mukhopadhyay, V., Sobieszczanski-Sobieski, J., Kosaka, I., Quinn, G., Charpentier, C.: Analysis, Design and Optimization of Non-cylindrical Fuselage for Blended-Wing-Body (BWB) Vehicle. AIAA Paper 2002-5664, 2002.

[31] Timoshenko, S. P., Woinowski-Krieger, S.: Theory of plates and shells. $2^{\text {nd }}$ ed., New York, USA, McGraw-Hill, 1959.

[32] Mukhopadhyay, V.: Structural concept study of non-circular fuselage configuration. AIAA/SAE World Aviation Congress, Los Angeles, USA, 1996, Paper WAC-67.

[33] Part 25. Airworthiness Standards: Transport Category Airplanes. In Code of Federal Regulations. Title 14. Aeronautics and Space. Washington, USA, Office of the General Register, 1995.

[34] Certification Specifications for Large Aeroplanes CS-25. Amendment 1. Köln, D, European Aviation Safety Agency, 2005.

[35] Wittmann, R.: Passenger acceptance of BWB configurations. Proceedings $24^{\text {th }}$ ICAS Congress, Yokohama, Japan, CD-ROM, 2004, paper 1.3.3.

[36] Roskam, J.: Airplane Design. Part 3. Layout design of cockpit, fuselage, wing and empennage: cutaways and inboard profiles. Ottawa (KA), USA, Roskam Aviation, 1986.

[37] Torenbeek, E.: Synthesis of subsonic airplane design. Delft, NL, Delft University Press, 1976. 
[38] Roskam, J.: Airplane Design. Part I. Preliminary sizing of airplanes. Ottawa (KA), USA, Roskam Aviation, 1985.

[39] Fielding, J. P.: Introduction to aircraft design. Cambridge, UK, Cambridge University Press, 1999.

[40] Raymer, D. P.: Aircraft design: a conceptual approach, $3^{\text {rd }}$ ed. Reston (VA), USA, AIAA, 1999.

[41] Joslin, R. D.: Aircraft Laminar Flow Control. Annual Review of Fluid Mechanics, Vol. 30 (1998), p. 1-29.

[42] Bewley, T. R.: Flow control: new challenges for a new Renaissance. Progress in Aerospace Sciences, Vol. 37 (2001), p. 21-58.

[43] Gad-el-Hak, M.: Flow control: The future. Journal of Aircraft, Vol. 38 (2001), p. 402-418.

[44] Martinez-Val, R. and Perez, E.: Optimum Cruise Lift Coefficient in Initial Design of Jet Aircraft. Journal of Aircraft, Vol. 29 (1992), p. 712-714.

[45] Martinez-Val, R., Pérez, E.: Extended Range Operations of Two and Three Turbofan Engined Airplanes. Journal of Aircraft, Vol. 30 (1993), p. 382-386.

[46] Clark, P.: Buying the big jets. Aldershot, UK, Ashgate, 2001.

[47] Vigneron, Y.: Commercial Aircraft for the $21^{\text {st }}$ Century-A380 and Beyond. AIAA/ICAS International Air E Space Symposium and Exposition, Dayton $(\mathrm{OH}), \mathrm{USA}, \mathrm{AIAA}$ Paper 2003-2886, 2003.

[48] Annex 14. Part 1, Aerodromes. Montreal, CND, International Civil Aviation Organisation, 2003.
[49] Turrado, E., Martinez-Val, R.: Impact of future generation aircraft in airport operativity and airspace capacity. Proceeding of ICRAT Conference, Zilina, Slovakia, 2004, p. 311-317.

[50] Martinez-Val, R., Hedo, J. M.: Analysis of Evacuation Strategies for Design and Certification of Transport Airplanes. Journal of Aircraft, Vol. 37 (2000), p. 440-447.

[51] Gerz, T., Holzäpfel, F., Darracq, D.: Commercial aircraft wake vortices. Progress in Aerospace Sciences, Vol. 38 (2002), p. 181-208.

[52] Hallock, J. N., Greene, G. C., Burnham, D. C.: Wake vortex research - A retrospective look. Air Traffic Control Quarterly, Vol. 6 (1998), p. 161-178.

[53] Ghigliazza, H. H., Martinez-Val, R., Perez, E., Smrcek, L.: On the wake of transport flying wings. Submitted for publication to Journal of Aircraft, 2006.

Prof. Dr. Rodrigo Martinez-Val

e-mail: rodrigo.martinezval@upm.es

ETSI Aeronauticos

Universidad Politecnica de Madrid

Plaza Cardenal Cisneros 3

28040 Madrid, SPAIN 